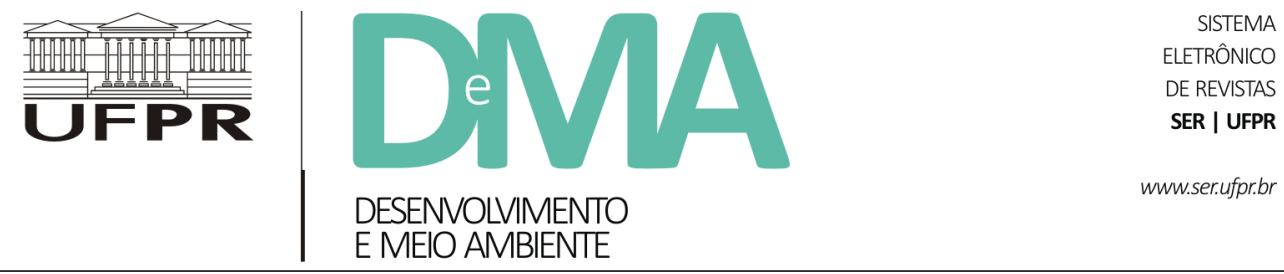

\title{
Identificação de serviços ecossistêmicos em áreas de floresta mediante sensoriamento remoto
}

\section{Identification of ecosystem services in forest areas through remote sensing}

\author{
Josianne Claudia Sales ROSA ${ }^{1 *}$, Barbara Almeida SOUZA ${ }^{1}$, Luis Enrique SÁNCHEZ1 \\ ${ }^{1}$ Departamento de Engenharia de Minas e de Petróleo, Universidade de São Paulo (USP), São Paulo, SP, Brasil. \\ *E-mail de contato: jcsrosa@usp.br
}

Artigo recebido em 7 de novembro de 2018, versão final aceita em 1 de abril de 2020, publicado em 19 de junho de 2020 .

RESUMO: $\quad$ O conceito de serviços ecossistêmicos tem ganhado espaço em processos de tomada de decisão e na gestão de projetos com potencial de causar significativa degradação ambiental, por explicitar a dependência que a sociedade tem dos benefícios ofertados pelos ecossistemas. Ao mesmo tempo, com o desenvolvimento de novos sensores e avanços tecnológicos, vem crescendo o uso de imagens de satélite como ferramenta do planejamento e gestão ambiental. O objetivo deste trabalho é a aplicação do sensoriamento remoto na identificação de ecossistemas, seus serviços e beneficiários para facilitar a aplicação do conceito de serviços ecossistêmicos ao planejamento e gestão ambiental. Mediante aplicação a uma mina de bauxita no Pará, em áreas de floresta amazônica de terra firme, são apresentadas as etapas para aplicação do conceito, desde o mapeamento da cobertura da terra até a identificação de beneficiários. Discute-se que duas técnicas, coleta de dados de campo com as comunidades e mapeamento da área por meio de classificação de imagens, são complementares. Os resultados mostram a aplicabilidade do sensoriamento remoto como ferramenta eficaz em suporte a identificação de serviços ecossistêmicos em contextos de planejamento e gestão ambiental.

Palavras-chave: classificação de imagens; mineração; recuperação de áreas degradadas; restauração ecológica.

ABSTRACT: The concept of ecosystem services has been used in decision-making processes and in the management of projects with the potential to cause significant environmental degradation, by explaining the dependence that society has on the benefits offered by ecosystems. In parallel, with the development of new sensors and technological advances, the application of satellite imagery to environment planning and management has also been growing. The objective of this work is to demonstrate the application of remote sensing to identify ecosystems, their services and beneficiaries, is order to facilitate the application of the ecosystem services concept to environmental planning and management. The steps for application, from land cover mapping to the identification of beneficiaries were tested in a bauxite mine located in the Amazon forest. Two techniques 
- collecting field data with communities and mapping the area through image classification -, are discussed as providing complementary input. Results demonstrate the applicability of remote sensing as an effective tool to support the identification of ecosystem services for environmental planning and management purposes.

Keywords: environmental impact assessment; remote sensing; mining; rehabilitation; ecological restoration.

\section{Introdução}

Projetos de desenvolvimento, como minerações, rodovias e barragens, modificam significativamente a estrutura e funcionamento dos ecossistemas de modo direto ou indireto, o que pode levar à perda de sua capacidade de fornecer benefícios à sociedade, os chamados serviços ecossistêmicos (Alcamo et al., 2003). Entende-se que o conceito de serviços ecossistêmicos promove uma análise integrada dos sistemas ecológico e social e por isso tem potencial de aprimorar o planejamento ambiental (Slootweg et al., 2009).

Identificar, avaliar e mitigar impactos de novos projetos sobre o fornecimento de serviços ecossistêmicos, com vistas a evitar, minimizar, recuperar ou compensar os efeitos adversos é boa prática internacional e exigência dos Padrões de Desempenho Socioambiental da Corporação Financeira Internacional desde 2012, como parte da avaliação prévia de impactos e riscos ambientais e sociais (Rosa \& Sánchez, 2015). A avaliação de impactos sobre serviços ecossistêmicos é pautada no pressuposto teórico da chamada cascata de fornecimento (Haines-Young \& Potschin, 2010), que mostra a relação entre os sistemas ecológicos e social. Segundo esse modelo teórico, o sistema ecológico, representado pela biodiversidade e processos ecológicos fornece determinados serviços ecossistêmicos a um grupo de pessoas, famílias, comunidades ou populações locais, chamados de beneficiários, que, por sua vez, podem obter os serviços diretamente como acesso a alimentos silvestres ou indiretamente como regulação da qualidade do ar, por exemplo. A forma de organização, modo de vida e demais características sociais representam o sistema social. A caracterização dos beneficiários é essencial para a aplicação do conceito de serviços ecossistêmicos, uma vez que sem beneficiário não há serviço (Fisher et al., 2009).

Os serviços ecossistêmicos são divididos em quatro categorias: de provisão, culturais, de regulação e de suporte (Hassan et al., 2005). Para fins de planejamento ambiental, especialmente avaliação de impactos, consideram-se apenas as três primeiras, uma vez que os serviços de suporte estão relacionados à manutenção do próprio sistema ecológico e, portanto, da conservação do ecossistema (Landsberg et al., 2013).

O primeiro e fundamental passo para avaliação de impactos de projetos sobre serviços ecossistêmicos ou outras aplicações, como o planejamento da recuperação de áreas degradadas (Rosa et al., 2020), é a identificação dos ecossistemas, bem como de seus serviços e beneficiários. Sendo assim, a identificação de serviços ecossistêmicos é feita em três passos: (i) identificação dos ecossistemas potencialmente afetados; (ii) identificação dos serviços fornecidos pelos ecossistemas; e (iii) identificação dos beneficiários que acessam esses serviços (Rosa \& Sánchez, 2016).

A identificação dos serviços ecossistêmicos é baseada no conceito de bacia de serviços (servi- 
ceshed), definido por Sheate et al. (2012), corroborado por Tallis et al. (2012), como uma unidade espacial que representa a relação entre o fornecimento de serviços e as pessoas que se beneficiam de tais serviços. Essa unidade inclui, portanto, a área onde os serviços são produzidos (os ecossistemas) e as áreas onde vivem as pessoas que se beneficiam desses serviços (beneficiários), bem como a região por onde elas transitam ao acessar os serviços.

Essa identificação requer, portanto, um mapeamento dos ecossistemas, de seus serviços e de seus beneficiários, o que por sua vez requer trabalhos de campo realizados em escala local, com a finalidade de confirmação do mapeamento dos ecossistemas, e para identificação dos beneficiários.

Os ecossistemas são formados por conjuntos de comunidades de plantas, animais, micro-organismos e pelo ambiente abiótico interagindo como uma unidade funcional (Hassan et al., 2005), que são, na prática, de difícil delimitação espacial. Como forma de direcionar tal dificuldade, a identificação dos serviços que os ecossistemas podem fornecer pode ser feita por meio de uma correlação entre classes de cobertura da terra (e, portanto, tipos de ecossistemas) e uma lista de serviços que cada tipo de ecossistema pode fornecer (Burkhard et al., 2012; Rosa \& Sánchez, 2016). As classes de cobertura da terra, por sua vez, são relacionadas a ecossistemas, cujo mapeamento é usualmente realizado mediante análise de bancos de dados espaciais (Paulin et al., 2020; Jacobs et al., 2015).

Assim, uma adequada classificação da cobertura e uso da terra pode otimizar os trabalhos de campo, que têm altos custos, podem ter longa duração, necessitam detalhamento compatível com a escala local e apresentam baixa capacidade de generalizações (Castro et al., 2008, Ayanu et al., 2012).
Em termos práticos, a informação básica para a identificação dos ecossistemas é um mapa de cobertura da terra (Ayanu et al., 2012; Barbosa et al., 2015), em escala adequada à análises ecológicas - geralmente de 1:20.000 até 1:50.0000 (Treweek, 1999). No Brasil, dada a insuficiência de informações georreferenciadas e ausência de mapas de cobertura da terra em escalas adequadas, é esperado que cada estudo gere seus próprios mapas, para os quais técnicas de sensoriamento remoto têm se mostrado úteis (Sánchez, 2013).

Historicamente, o sensoriamento remoto tem sido utilizado para monitorar mudanças no uso e cobertura da terra, otimizando trabalhos de campo. Com o surgimento de novos e mais sofisticados satélites, os dados de observação da Terra podem contribuir para identificação e mapeamento de serviços ecossistêmicos, se associados a bem planejados trabalhos de campo para coletas de dados sociais (Paudyal et al., 2015).

Neste artigo, cujo objetivo é identificar serviços ecossistêmicos mediante sensoriamento remoto para fins de atividades de planejamento ambiental, foram processadas imagens do satélite RapidEye de uma área de estudo que abrange uma mina de bauxita no município de Juruti, Pará.

Nessa mina, ecossistemas de terra firme (CNEC, 2005) são afetados pela supressão da vegetação, ao passo que, após a extração do minério, são realizadas ações de recuperação ambiental visando restaurar o ecossistema florestal. A supressão de vegetação afeta a floresta ombrófila densa, que fornece serviços de provisão como alimentos silvestres, madeira e regulação do clima global (Rosa et al., 2018). 


\section{Caracterização do caso em estudo}

Em 2005, teve início o processo de licenciamento ambiental do "Projeto Mina Juruti", com a finalização do Estudo de Impacto Ambiental (EIA) (CNEC, 2005). O projeto é composto por uma mina, uma usina de concentração mineral, três bacias de disposição de rejeito, estruturas de apoio, um porto fluvial e uma ferrovia de $55 \mathrm{~km}$ que liga a mina ao porto, localizado às margens do rio Amazonas. A extração mineral é feita por lavra em tiras, o que facilita o processo de recuperação ambiental, uma vez que, quase imediatamente após a lavra são implementadas ações de recuperação da área mediante reposição de solo superficial e favorecimento da germinação de espécies nativas (Wang et al., 2011).

A área afetada pelo projeto é composta principalmente por duas formas de relevo, os platôs onde se localizam os depósitos de bauxita, com altura de 70120 metros em relação ao nível do rio Amazonas, e as encostas, áreas próximas a cursos d'água (Antoniassi, 2010). O depósito de bauxita ocorre nos platôs próximo ao Lago Grande de Juruti, às margens do rio Amazonas e situado em uma planície fluvial alagada, caracterizada geomorfologicamente como "lago de barragem" (lago natural), que ocorre a jusante de rios que têm sua foz afogada ou barrada (CNEC, 2005).

O perfil geológico típico do platô apresenta, essencialmente, a mesma sequência de horizontes, sendo essa uma camada superficial de argila caulinítica com espessura de 8-10 metros, a zona mineralizada, onde é encontrada a bauxita, com espessura de 1-3 metros, e uma zona saprolítica ou argilosa que varia de 1-6 metros (Antoniassi, 2010). Essa região é coberta por floresta ombrófila densa submontana (MME/DNPM, 1976; CNEC, 2005).

A população de Juruti é predominantemente rural e há comunidades ribeirinhas ao longo do Lago Grande que desenvolvem atividades de extrativismo vegetal, pesca e agricultura em pequena escala. Houve aumento de $51 \%$ da população do município (IBGE, 2011), principalmente na área urbana, mas também nas pequenas vilas ao longo do Lago Grande de Juruti no período de 2000 a 2010. A extração mineral ocorre dentro do território de um Projeto de Assentamento Extrativista (PAE) denominado Juruti Velho, cuja criação data de 2005 e a titulação coletiva foi concedida em 2009.

\section{Metodologia}

As etapas para avaliação de impactos sobre o fornecimento de serviços ecossistêmicos, descritas por Landsberg et al. (2013) e testadas por Rosa \& Sánchez (2016), foram aplicadas para a identificação de ecossistemas, serviços e seus beneficiários.

Para tanto, foi feita uma classificação de imagens de uma área da mineração de bauxita. Foram utilizadas imagens do satélite RapidEye, com resolução espacial de $5 \mathrm{~m}$. As imagens foram obtidas gratuitamente pelo site "Geocatálogo", do Ministério de Meio Ambiente, processadas (classificação não supervisionada e supervisionada) no programa de sensoriamento remoto, ENVI $5.3^{2}$. A metodologia de processamento das imagens estruturou-se em etapas sequenciadas (Figura 1).

A etapa inicial foi o pré-processamento das imagens, que consistiu nas atividades preparatórias do sensoriamento remoto: aquisição das imagens e aplicação

\footnotetext{
${ }^{1}$ Imagens adquiridas pelo sitio na internet http://geocatalogo.mma.gov.br/ em agosto de 2016.

${ }^{2}$ Licença adquirida pelo departamento de Engenharia de Minas e de Petróleo da EPUSP.
} 
de contraste. Depois, seguiu-se para a classificação não supervisionada, visando o reconhecimento preliminar da área, e então para a Análise da Componente Principal (ACP) que permitiu a verificação de elementos não visíveis na imagem composta. AACP permite o tratamento de imagens com elevado número de bandas espectrais e a obtenção de informações de dados multitemporais (Crósta, 2002).

A partir dos resultados da ACP e da classificação não supervisionada, foram realizados trabalhos de campo para capturar amostras das classes de cobertura da terra, conforme metodologias empregadas por Jensen (2009) e Lillesand et al. (2008), em que as classes de uso são mapeadas a partir de dados digitais detectados remotamente por meio de classificação e interpretação de imagens digitais. O objetivo geral do procedimento de classificação de imagens é categorizar automaticamente todos os pixels em uma imagem em classes ou temas de cobertura do solo.

A etapa de classificação supervisionada foi realizada a partir de uma cuidadosa coleta de amostras, utilizando o algoritmo "Maximum Likelihood" do software ENVI, mantendo o foco somente na área de interesse, para diminuir interpretações conflitantes entre as classes. Foi feita a análise de acurácia a partir da matriz de confusão. A partir do mapeamento da área, foi possível identificar os serviços ecossistêmicos potencialmente afetados, seguindo a metodologia de

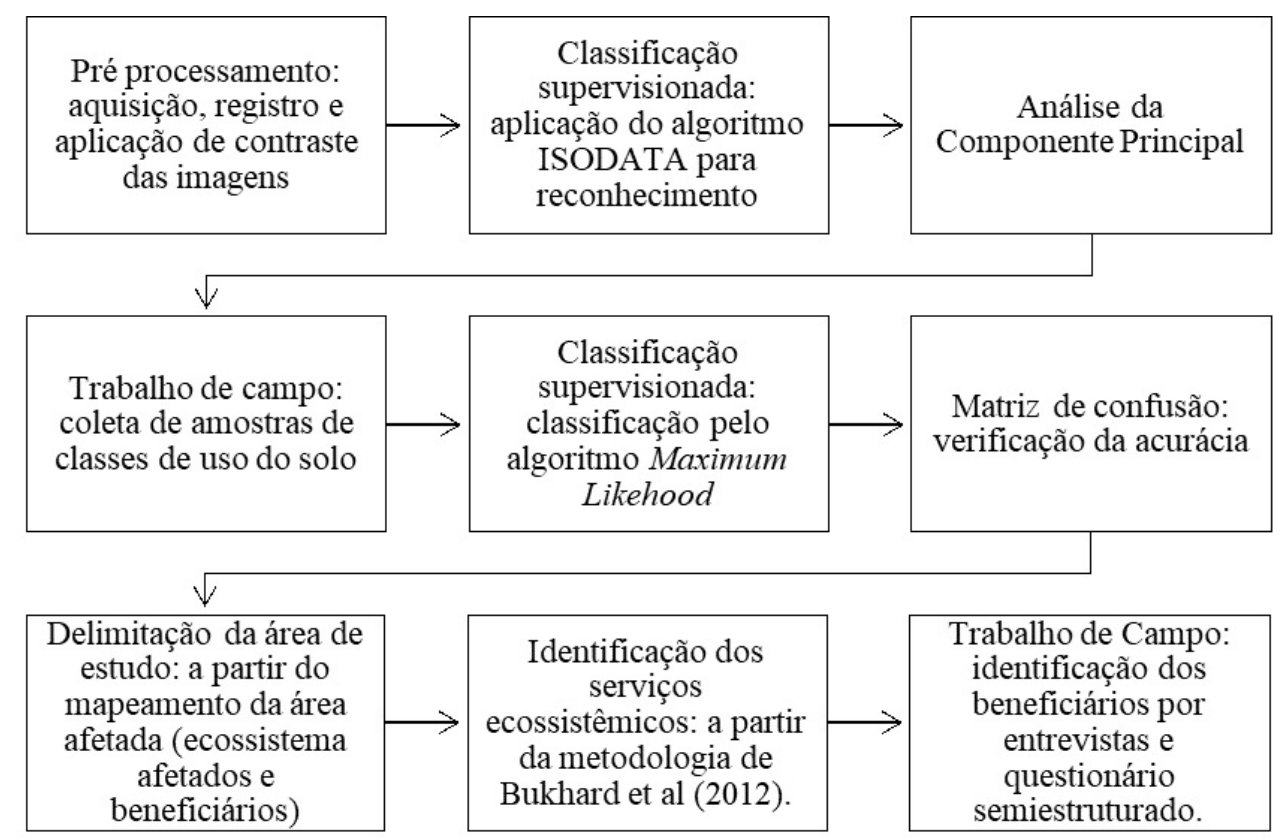

FIGURA 1 - Fluxograma da metodologia da pesquisa que apresenta as etapas sequenciadas realizadas iniciando do pré-processamento de imagens até a aplicação do questionário. 
Burkhard, et al. (2012), e seus beneficiários, por meio de aplicação, em campo, de questionários (Rasmussen et al., 2016). O mapeamento também foi útil para otimizar a realização do segundo trabalho de campo, que objetivou a aplicação dos questionários focados em comunidades mais próximas e/ou com acesso aos ecossistemas potencialmente afetados pelo projeto.

A identificação de beneficiários de serviços ecossistêmicos só foi possível a partir de trabalhos de campo. Utilizamos as informações coletadas por meio da interpretação da imagem de satélite com objetivo de selecionar as comunidades para aplicação dos questionários, assim como fizeram Castro et al. (2008), ao planejar um levantamento em área rural na Colômbia.

Do total de 52 comunidades existentes no PAE Juruti Velho, foram selecionadas quatro como beneficiários diretos dos ecossistemas do platô denominado Capiranga (em explotação em 2016): Pompom, Capiranga, Jauri e Pau d'Arco. O questionário foi construído com objetivo de compreender como as comunidades utilizavam as áreas antes da mineração (Gunther, 2003). Foram aplicados 19 questionários entre os dias 1 e 17 de agosto de 2016. Durante a aplicação dos questionários, não houve preocupação de realizar uma amostragem representativa porque o objetivo foi demonstrar a aplicabilidade do procedimento, por meio de exemplos, e não realizar um diagnóstico exaustivo.

\section{Resultados e discussão}

\subsection{Identificação de ecossistemas}

A partir da ACP foi possível constatar que somente a floresta ombrófila densa (floresta de terra firme) é afetada pela operação da mina, uma vez que, a zona mineralizada encontra-se somente no platô. Os ecossistemas aquáticos (rios e lagos) e a florestal ombrófila densa aluvial não são afetados pelo processo de extração mineral, devido a preservação de uma borda de vegetação nativa nos platôs. AACP também realçou as formas naturais de relevo, destacando a borda do platô e as cabeceiras de drenagens, que se localiza na encosta dos platôs (Tabela 1). Sendo assim, serviços ecossistêmicos fornecidos pelos rios e lagos - como pesca, fornecimento de água etc. não são potencialmente afetados pelo projeto de mineração.

A partir da análise da componente principal e classificação não supervisionada, foi planejada a coleta de dados para servirem como referências ou "verdades" de campo. Para cada classe pré-definida como regiões de interesse, foi coletado pelo menos um ponto de referência (Figura 2), que foi utilizado para testar a classificação supervisionada por meio da matriz de confusão (Figura 3).

Além das referências de campo, o empreendedor forneceu arquivos no formato Shapefile das áreas que estão sendo recuperadas de acordo com o ano em que a recuperação foi iniciada (Figura 3). Com a classificação supervisionada, foi possível identificar uma concentração de áreas em processo de recuperação. Essa classe foi diferenciada tanto da vegetação nativa, quanto da vegetação degradada (áreas que sofreram distúrbios, mas não que não houve remoção total da vegetação) no entorno direto do empreendimento e de estradas e acessos (Figura 3). 
TABELA 1 - Resultados da Análise da Componente Principal (ACP) na área de estudo, que apresenta a identificação do componente, a imagem gerada pela ACP e a sua interpretação.

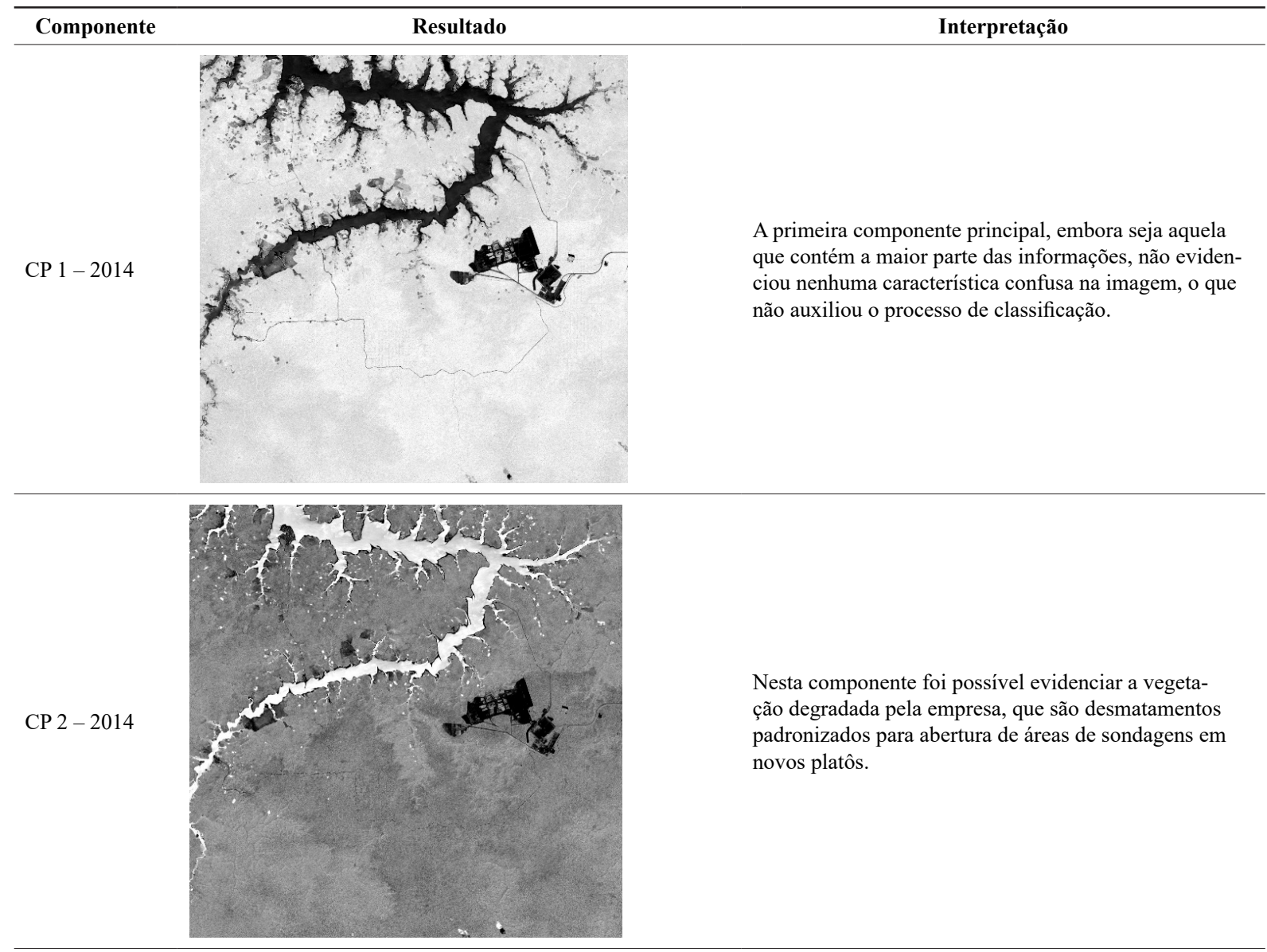

CP $3-2014$

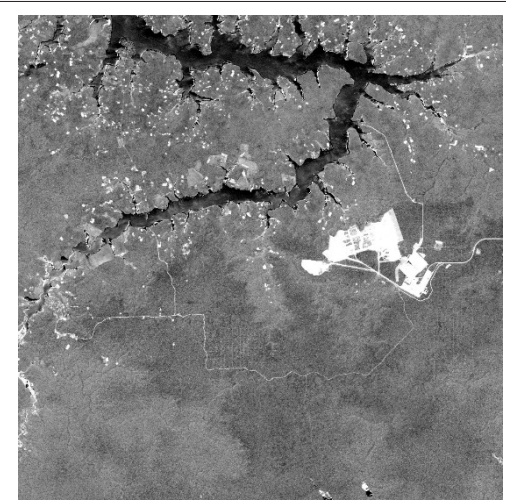

A primeira componente principal, embora seja aquela contem a maior parte das informações, não evidenciou nenhuma característica confusa na imagem, o que não auxiliou o processo de classificação.
Na terceira componente principal, embora tenha menos informações que as duas anteriores, evidenciou a abertura de clareiras de vegetação próximas ao rio, que provavelmente são áreas utilizadas pelas comunidades ribeirinhas. 


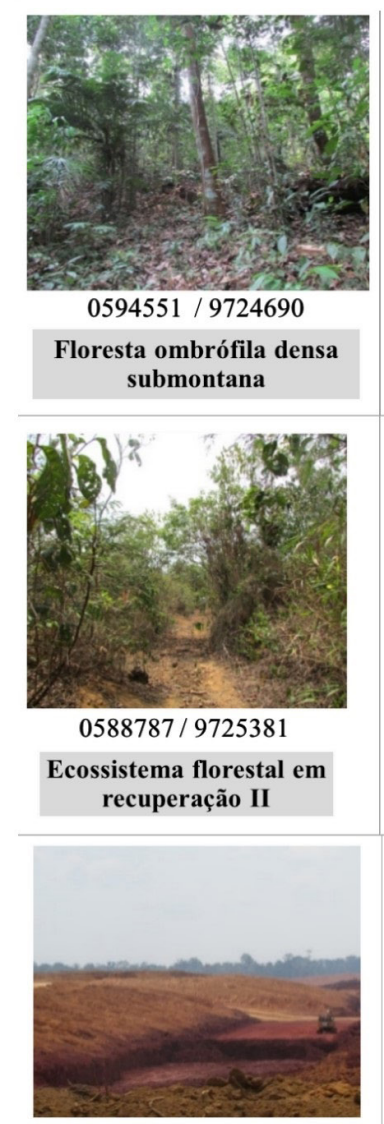

$0591689 / 9723873$
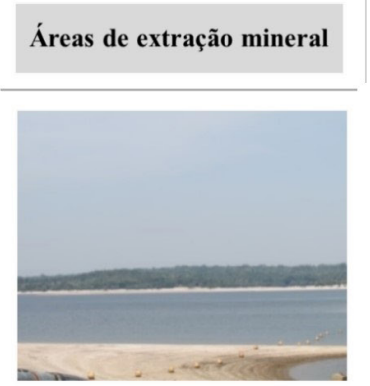

$0592549 / 9721998$

Rios e Lagos

FIGURA 2 - Foto dos pontos de interesse coletados em campo para classificação supervisionada da área de estudo. Coordenadas em UTM Zona 23S.

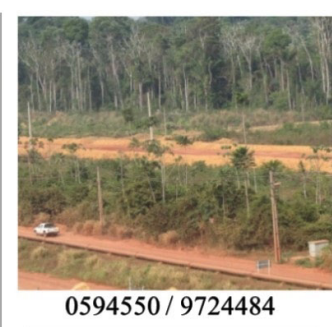

Ecossistema florestal em recuperação I

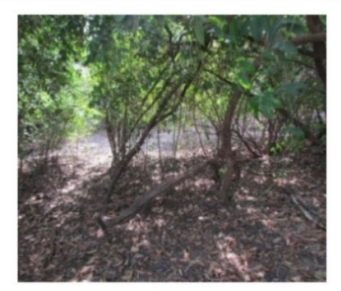

$0589073 / 9730913$

Floresta ombrófila densa aluvial

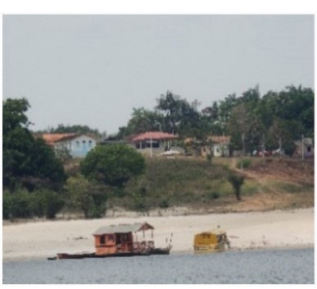

$0586799 / 9729160$

Mosaico de usos

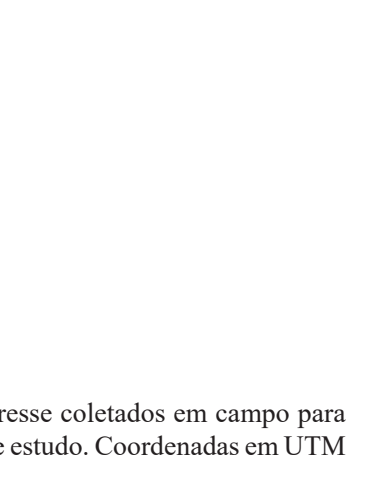

O foco de confusão na classificação se concentrou na diferenciação entre as classes "ecossistema florestal em recuperação I e II" (Tabela 2). Uma vez que uma refere-se a uma vegetação que não foi totalmente removida, mas foi degradada pelo empreendimento e a outra refere-se às áreas onde a vegetação foi completamente removida e ações de recuperação foram implementados.

Ainda que o erro de omissão tenha sido alto, ou seja o algoritmo deixou de classificar 51\% dos pixels da classe "Ecossistema florestal em recuperação II", poucos pixels de outras classes foram considerados pertencentes desta classe (erro de comissão).

De posse dessa informação, foi possível confirmar que a maior parte da classificação está correta. Algumas áreas indicadas pelo empreendedor em que a recuperação foi iniciada em 4 , foram classificadas como área de extração mineral, porque esse processo começou depois da captura da imagem. Portanto, considera-se que a classificação supervisionada foi razoável para diferenciar os ecossistemas na área de estudo.

\subsection{Identificação de serviços ecossistêmicos}

A partir do mapa de cobertura da terra, que diferencia os ecossistemas afetados, foi possível identificar o potencial de fornecimento de serviços ecossistêmicos. Ainda que o mapa de cobertura não demonstre o fornecimento de serviços ecossistêmicos, este por si só auxilia o processo de identificação dos serviços e espacialização da análise. O mapa é também um instrumento de comunicação com os beneficiários afetados, para que estes possam ser envolvidos no planejamento ambiental de um empreendimento. 


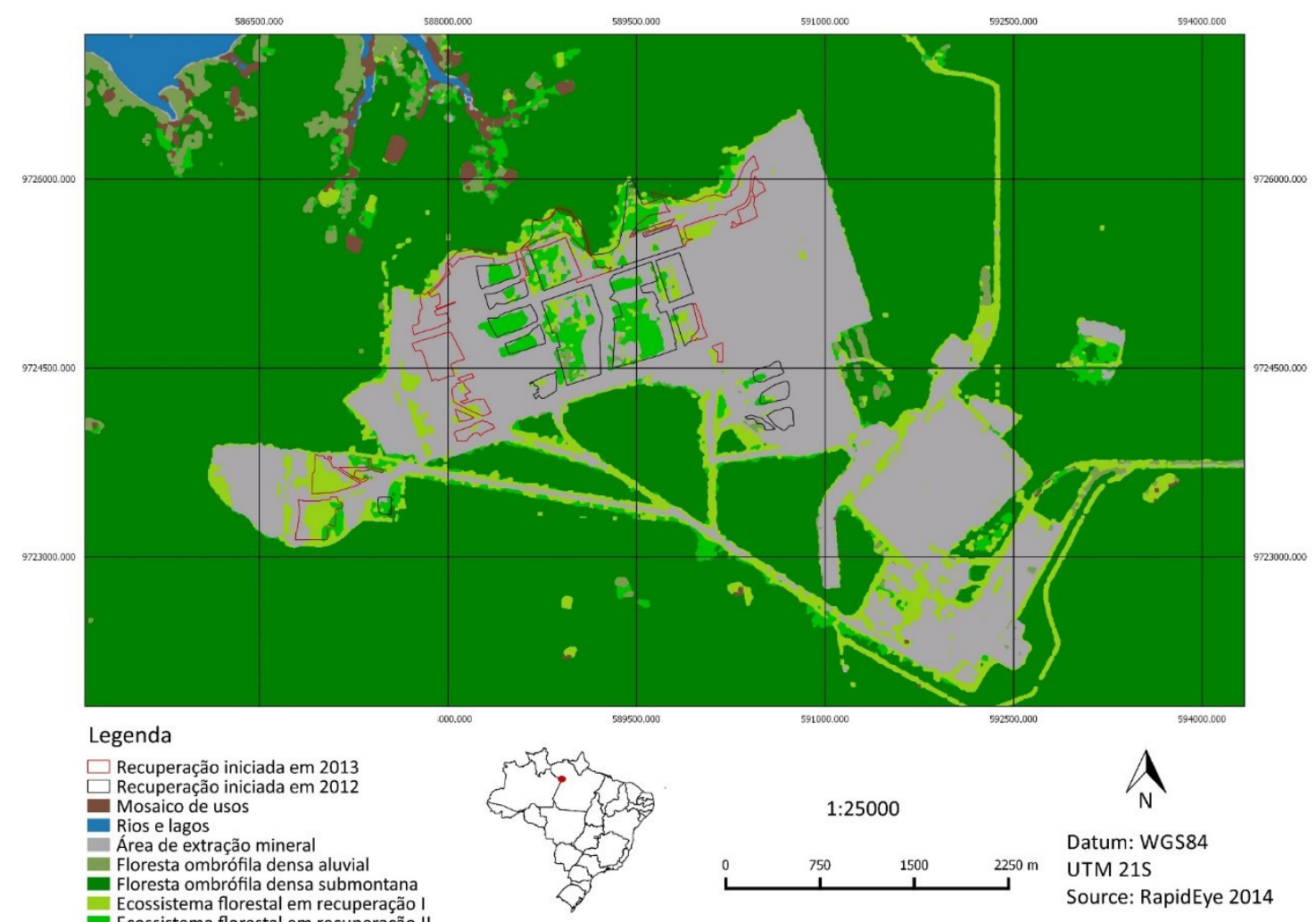

FIGURA 3 - Mapa de cobertura da terra da área de estudo a partir da classificação supervisionada da imagem do satélite RapidEye, 2014.

TABELA 2 - Erro de comissão e omissão para classificação da imagem do satélite RapidEye 2014, separado por classe de cobertura do solo.

\begin{tabular}{lcccc}
\hline \multicolumn{1}{c}{ Classe } & $\begin{array}{c}\text { Comissão } \\
(\mathbf{\%})\end{array}$ & $\begin{array}{c}\text { Omissão } \\
(\%)\end{array}$ & Comissão (pixels) & Omissão (pixels) \\
\hline Rios e lagos & 0 & 0 & $0 / 88868$ & $0 / 88868$ \\
Área de extração mineral & 0,96 & 2,08 & $353 / 36897$ & $778 / 37322$ \\
Mosaicos de usos & 91,69 & 99,04 & $684 / 746$ & $6413 / 6475$ \\
Ecossistema florestal em recuperação II & 2,59 & 51,04 & $684 / 746$ & $2976 / 5831$ \\
Ecossistema florestal em recuperação I & 80,04 & 31,59 & $10320 / 12893$ & $1188 / 3761 /$ \\
Floresta ombrófila densa submontana & 0,01 & 15,31 & $26 / 235545$ & $42579 / 278098$ \\
Floresta ombrófila densa aluvial & 69,94 & 10,01 & $44540 / 63684$ & $2129 / 21273$ \\
\hline
\end{tabular}


Economicamente, a região de Juruti é marcada pelo extrativismo (Monzoni et al., 2008) e constata-se que a floresta oferta serviços às comunidades locais. A floresta ombrófila densa, antes do processo de extração mineral, representa o ecossistema de referência e, portanto, é considerada o ponto máximo de fornecimento do serviço. Ecossistema de referência é um ecossistema natural, que pode ser utilizado como modelo ou objetivo para o planejamento da restauração ecológica e posteriormente para avaliação de seus resultados (SER, 2004; Aronson et al., 2010). Por outro lado, a área extração mineral representa o ápice de degradação, onde não há fornecimento de serviços ecossistêmicos.

Os serviços ecossistêmicos da área em estudo foram identificados, a partir das classes de cobertura do solo, cujo mapeamento possibilitou a identificação dos ecossistemas, mais as informações observadas em campo e as informações extraídas do EIA do empreendimento (Tabela 3). Por questão de apresentação, apenas os serviços fornecidos nessa área foram mantidos na matriz.

\subsection{Identificação dos beneficiários}

Os resultados da classificação das imagens de satélite foram a base para o planejamento dos trabalhos de campo com objetivo de identificar os beneficiários dos serviços ecossistêmicos. A mina afeta diretamente as comunidades que compõem o Programa de Assentamento Agroextrativista - PAE Juruti Velho, que é composto por 52 comunidades. Desse total foram selecionadas cinco como beneficiários diretos do platô Capiranga (atualmente em explotação).
O roteiro (Anexo 1) de entrevistas (Gunther, 2003) foi construído com objetivo de compreender como as comunidades utilizavam as áreas antes da mineração e com isso identificar serviços ecossistêmicos prioritários, conforme metodologia aplicada por outros autores (Paudyal et al., 2015; CNEC, 2005). Cabe destacar que a aplicação dos questionários não teve como objetivo a realização de um diagnóstico exaustivo e sim houve uma demonstrar a aplicabilidade do procedimento.

Todos os entrevistados nasceram em Juruti e afirmaram que a principal forma de lazer das comunidades são festividades religiosas e recreações, seja jogar bola, brincar no rio ou soltar pipa. A maioria dos entrevistados relatou que não há atividades culturais junto a natureza ou as florestas. Apenas três entrevistados relataram que antes da mineração ocorria a festa da castanha em época de colheita, realizada com objetivo de comemorar a colheita. A principal forma de abastecimento de água das comunidades é um microssistema de captação de água de poço, construído pela prefeitura. Apenas duas famílias responderam que utilizam água diretamente do rio, isso ocorre em casas que são mais isoladas das sedes das comunidades, e apenas uma utiliza água de nascente. Sobre os usos do rio, todas as famílias relataram que o utilizam para tomar banho, dessedentação de animais, lazer, pesca e lavagem de roupas.

A segunda seção do questionário focou na identificação dos serviços ecossistêmicos da região. Em outras palavras, o objetivo dessa seção foi compreender como as comunidades utilizavam as florestas de platô. Os resultados indicaram que as atividades realizadas eram coletar principalmente castanha do Pará (Bertholletia excelsa) (serviço: Alimentos silvestres), cipós Ambé (Philodendron sp), Titica (Heteropsis spp.) e outras espécies de cipós (Serviço: 
TABELA 3 - Matriz de identificação de serviços ecossistêmicos fornecidos, a partir das classes de cobertura da terra mapeadas.

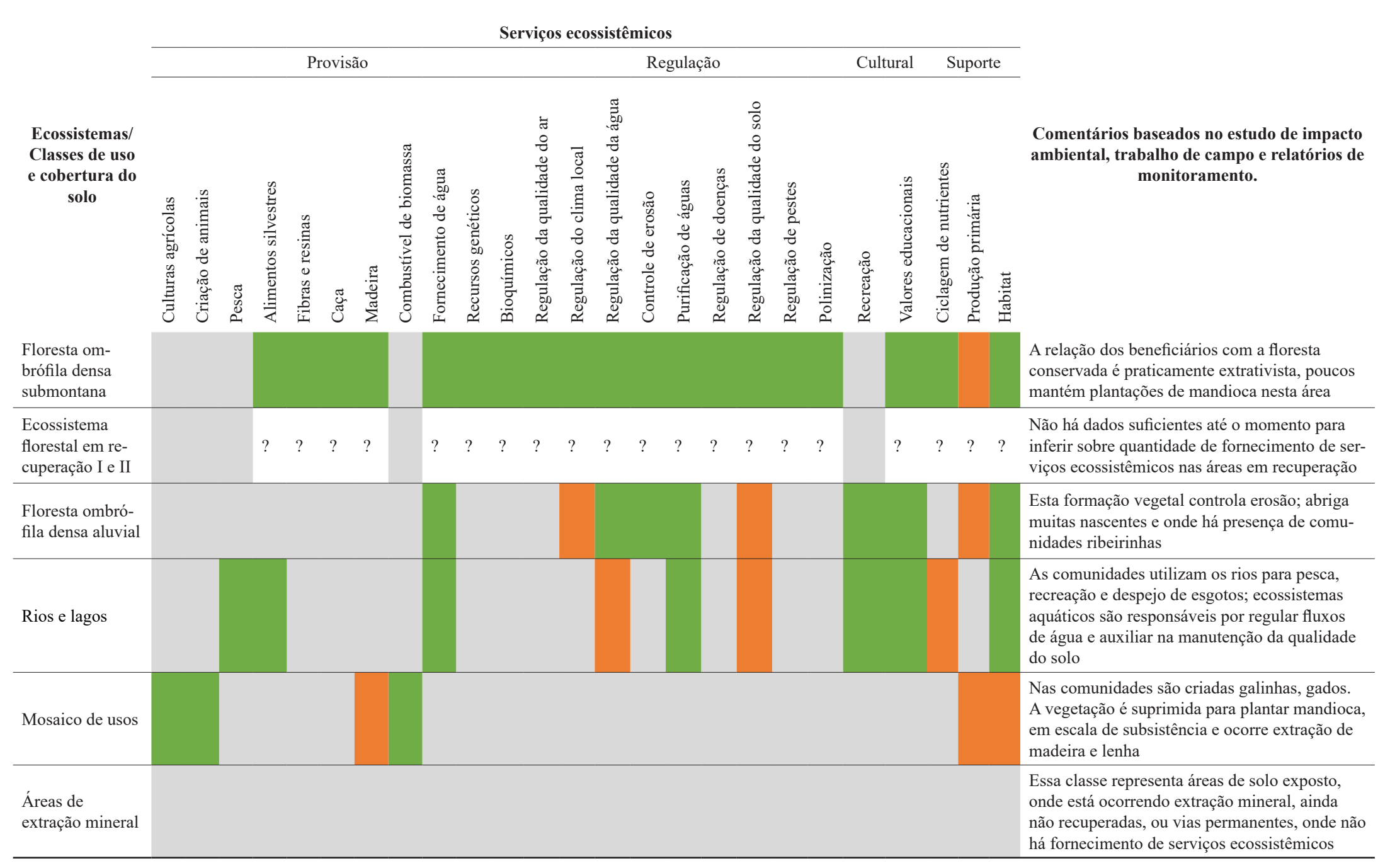

FONTE: Baseado em Burkhard et al. (2012).

NOTA: Verde: Potencial máximo de fornecimento do serviço, Laranja: Potencial médio de fornecimento de serviço, Cinza: Não há fornecimento. 
resinas e fibras) utilizadas para construir paneiro, utensílio para coleta das castanhas. Além disso, os entrevistados afirmam que coletavam plantas medicinais (serviço: Medicina natural), como andiroba (Carapa guianensis) e copaíba (Copaifera langsdorffii), nas áreas onde hoje a mineração ocorre. As áreas de platôs eram também utilizadas para extração de madeira, especialmente itaúba (Mezilaurus itauba) (serviço: Madeira), utilizada na construção de casas, canoas e remos.

A caça é frequente na região até os dias atuais, sendo cutias (Dasyprocta sp), veados (Mazama sp), tatus (Dasypus sp e Tolypeutes sp), pacas (Cuniculus paca) e antas (Tapirus terrestres) os animais mais visados. A caça foi prejudicada pela atividade de mineração devido à supressão de vegetação e geração de ruídos, que afugentam a fauna. A maioria dos entrevistados relatou que gostaria de voltar a realizar tais atividades novamente, embora tenham se dividido ao serem perguntados que se achavam que seus filhos e netos poderiam querer realizar tais atividades.

Quando perguntados se a mineração atualmente interfere negativamente suas atividades, 70\% dos entrevistados responderam que não, os outros afirmaram que a mineração atrapalha principalmente a atividade de caça e a retirada de madeira, que são serviços fornecidos pela floresta ombrófila densa submontana, localizada nos platôs. Dentre os serviços fornecidos pela região que não foram afetados pela mineração destaca-se culturas agrícolas (plantações de mandioca) e lenha (combustível de biomassa) utilizada na produção de farinha, porque são atividades desenvolvidas próximas às casas dos beneficiários e não apresentam relação com a floresta ombrófila densa submontana que ocorre nos platôs. Os serviços fornecidos pelos rios e lagos e pela floresta ombrófila densa aluvial, como pesca, fornecimento de água, re- creação, regulação da qualidade da água, controle de erosão, purificação da água não foram afetados pelo empreendimento. Tal fato se deve pela constatação da manutenção do relevo e da vegetação nativa na borda do platô que impede que processos erosivos cheguem aos cursos d'água da região. Portanto, ao utilizar o conceito de serviços ecossistêmicos deve-se atentar principalmente a análise integrada dos dados e ao encadeamento metodológico que a cascata de fornecimento de serviços ecossistêmico pressupõe (Rosenthal et al., 2015). A aplicação do conceito de serviços ecossistêmicos é fundamentada na análise e quantificação do sistema ecológico que representa o fornecimento de serviços, mas é também baseada na análise e quantificação do sistema social, que representa a demanda pelos serviços (Geneletti, 2016; Pires et al., 2018).

A coletar dados ecológicos e sociais deve ser analisada caso a caso após o mapeamento dos ecossistemas, por meio de um mapa de cobertura da terra. Há recomendações para uma combinação de métodos que demonstrem o modo de vida e utilização dos serviços pelos beneficiários (Rasmussen et al., 2016). A escolha desses métodos deve considerar os custos financeiros e a disponibilidade de tempo para realizar trabalhos de campo. Esse artigo demonstra como o sensoriamento remoto pode auxiliar o planejamento do trabalho de campo de forma a minimizar os custos e tempo, sem prejudicar a qualidade dos dados (Castro et al., 2008).

O sensoriamento remoto é também alternativa para monitorar os avanços ecológicos da recuperação, evitando os altos custos da coleta de dados em campo que as crescentes áreas mineradas impõe. $\mathrm{O}$ mapeamento feito por Vasuki et al. (2018), baseado em interpretação de imagens, para uma mina na Austrália Ocidental é um exemplo de monitoramento por 
meio de imagens de satélite com vistas a monitorar a recuperação ambiental. O monitoramento da estocagem de carbono, um tema de interesse global, pode ser feito a partir de sensoriamento remoto, por meio de laser aerotransportados (tecnologia LIDAR - Light Detection and Ranging) para estimar a altura total das árvores, fornecendo uma medida mais acurada do que a estimativa por um observador em campo (Lefsky et al., 2002).

\section{Conclus̃̃es}

Neste artigo, demonstrou-se como o sensoriamento remoto é útil para realizar o primeiro passo da análise de serviços ecossistêmicos, a identificação de ecossistemas, seus serviços e beneficiários. Como a identificação de serviços ecossistêmicos está fortemente relacionada às características biofísicas e sociais da região, essa é dependente da resolução espacial da imagem de satélite utilizada. Portanto, apresentar e discutir os dados da classificação utilizada para desenvolvimento do mapa de cobertura do solo é essencial para determinar a eficácia da identificação dos serviços ecossistêmicos.

A identificação de beneficiários de serviços ecossistêmicos só foi possível a partir de trabalhos de campo. Trabalhos de campo são custosos e por isso seu planejamento deve ser cuidadosamente realizado. Utilizamos as informações coletadas durante o mapeamento da área de estudo para selecionar as comunidades alvo do trabalho de campo. Neste sentido, a utilização do sensoriamento remoto auxilia a identificação e mapeamento de serviços em áreas com poucos dados disponíveis ou com acesso limitado, como é o caso frequente da atividade minerária.

\section{Agradecimentos}

À Fundação de Amparo à Pesquisa de São Paulo (FAPESP/CAPES 2014/22927-1) pela concessão de bolsa de estudo à primeira autora. Ao Ministério de Meio Ambiente (MMA), pelo fornecimento gratuito das imagens de satélite do sensor RapidEye. À empresa Alcoa do Brasil, pela permissão de acesso a área de estudo, fornecimento de documentos e acompanhamento durante os traba1hos de campo. Ao departamento de Engenharia de Minas e de Petróleo da Escola Politécnica, Universidade de São Paulo, pela aquisição dos softwares ENVI 5.3 para processamento das imagens e o pacote Office 2015 para desenvolvimento do trabalho.

\section{Referências}

Alcamo, J. Ash N. J.; Butler. C. D.; Callicott J. B.; Capistrano D.; Zurek M. B. Ecosystems Ecosystems and Human Well-Being: A Framework for Assessment. Washington: Island Press, 2003.

Antoniassi, J. L. A Difração de raios X com o método de Rietveld aplicada a bauxitas de Porto Trombetas, PA. Dissertação (Mestrado). Escola Politécnica da Universidade de São Paulo, 2010.

Aronson, J.; Blignaut, J. N.; Milton, S. J.; Maitre, D. L.; Esler, K. J.; Limouzin, A.; Fontaine, C.; Wit, M. P. de; Mugido, W.; Prinsloo, P.; Elst, L. van der; Lederer, N. Are socioeconomic benefits of restoration adequately quantified? A meta-analysis of recent papers (2000-2008) in Restoration Ecology and 12 other scientific journals. Restoration Ecology, 18(2), 143-154, 2010. doi:10.1111/j.1526100X.2009.00638.x

Ayanu, Y. Z.; Conrad, C.; Nauss, T.; Wegmann, M.; Koellner, T. Quantifying and mapping ecosystem services supplies and demands: a review of remote sensing applications. Environmental science \& technology, 46(16), 8529-8541, 


\section{2. doi: $10.1021 / \mathrm{es} 300157 \mathrm{u}$}

Barbosa, C. C. A.; Atkinson, P. M.; Dearing, J. A. Remote sensing of ecosystem services: a systematic review. Ecological indicators, 52, 430-443. 2015. doi: 10.1016/j. ecolind.2015.01.007

Burkhard, B.; Kroll, F.; Nedkov, S.; Muller, F. Mapping ecosystem service supply, demand and budgets. Ecological Indicators, 21, 17-29, 2012. doi: 10.1016/j.ecolind.2011.06.019

Castro, F.; Silva-Forberg, M. C.; Wilson, W.; Brondizio, E. S.; Moran, E. F. Uso de sensoriamento remoto em levantamento rápido rural: uma experiência na Colômbia. In: Batistella, M.; Moran, E. F. (Orgs.). Geoinformação e monitoramento ambiental na América Latina. São Paulo: Editora Senac, 2008.

CNEC - Consórcio Nacional de Engenheiros Construtores. Estudo de Impacto Ambiental do Projeto Juruti: Identificação, caracterização e avaliação de impactos ambientais. Juruti, 2005.

Crósta, A. P. Processamento Digital de Imagens de Sensoriamento Remoto. Campinas: IG/UNICAMP, 4. ed., 2002.

Fisher, B.; Turner, K.; Morling, P. Defining and classifying ecosystem services for decision marking. Ecological Economics, 68, 643-53, 2009. doi: 10.1016/j.ecolecon.2008.09.014

Geneletti D. (Ed.). Handbook on Biodiversity and ecosystem services in impact assessment. Cheltenham, UK; Northampton, MA, USA: Edward Elgar Publishing, 2016.

Gunther, H. Como elaborar um questionário? Laboratório de Psicologia Ambiental. Série: Planejamento de Pesquisa de Pesquisa nas Ciências Sociais. Brasília: Universidade de Brasília, 2003.

Haines-Young, R.; Postchin, M. The links between biodiversity, ecosystem services and human well-being. In: Raffaelli, D. G.; Frid, C. L. J. (Eds.). Ecosystem Ecology: A new synthesis. Cambridge: Cambridge University Press, 2010. p. 110-139.

Hassan, R. M.; Scholes, R.; Ash, N. Ecosystems and Human Well-Being: current state and trends. Washington: Island Press, 2005.
IBGE - Instituto Brasileiro de Geografia e Estatística. Censo demográfico, 1940-2010. 2011. Disponível em: <http:// www.ibge.gov.br>. Acesso em: abr. 2016.

Jacobs, S.; Burkhard, B.; Van Daele, T.; Staes, J.; Schneiders, A. The Matrix Reloaded: A review of expert knowledge use for mapping ecosystem services. Ecological Modelling, 295, 21-30, 2015. doi:10.1016/j.ecolmodel.2014.08.024

Jensen, J. R. Sensoriamento Remoto do ambiente: uma perspectiva em recursos terrestres. São José dos Campos: Parêntese, 2009.

Landsberg, F.; Treweek, J.; Mercedes, S. M.; Henninger, $\mathrm{N}$.; Venn, O. Weaving ecosystem services into impact assessment. Version 1.0. Washington, DC: World Resources Institute, 2013.

Lefsky, M. A.; Cohen, W. B.; Harding, D. J.; Parker, G. G.; Acker, S. A.; Gower, S. T. Lidar remote sensing of above-ground biomass in three biomes. Global Ecology Biogeography, 11, 393-399, 2002. doi:10.1046/j.1466822x.2002.00303.x

Lillesand, T. M.; Kiefer, R. W.; Chipman, J. W. Remote sensing and image interpretation. Hoboken, NJ: John Wiley \& Sons, 6. ed., 2008.

MME - Ministério de Minas e Energia. DNPM - Departamento Nacional de Produção Mineral. Projeto Radam Brasil - Programa de integração nacional. Folha SA.21-Santarém; geologia, geomorfologia, pedologia, vegetação e uso potencial da terra. Levantamento de recursos naturais. Vol. 10. Rio de Janeiro, 1976.

Monzoni, M.; Biderman, R.; Ferraz, C.; Pinto, D. G. Juruti Sustentável: uma proposta de modelo para o desenvolvimento local. Gvces e Funbio. S.l: Biblioteca Digital FGV, 2008. Disponível em: <http://hdl.Handle.Net/10438/18488>. Acesso em: mar. 2020.

Paudyal, K.; Baral, H.; Burkhard, B.; Bhandari, S. P.; Keenan, R. Participatory assessment and mapping of ecosystem services in a data-poor region: Case study of community-managed forests in central Nepal. Ecosystem Services, 13, 81-92, 2015. doi: 10.1016/j.ecoser.2015.01.007

Paulin, M. J.; Remme, R. P.; van der Hoek, D. C. J.; de Knegt, B.; Koopman, K. R.; Breure, A. M. et al. Towards 
nationally harmonized mapping and quantification of ecosystem services. Science of the Total Environment, 703, 134973, 2020. doi:10.1016/j.scitotenv.2019.134973

Pires, A. P. F.; Amaral, A. G.; Padgurschi, M. C. G.; Joly, C. A.; Scarano, F. R. Biodiversity research still falls short of creating links with ecosystem services and human well-being in a global hotspot. Ecosystem Services, 34, 68-73, 2018. doi: 10.1016/j.ecoser.2018.10.001

Rasmussen, L. V.; Mertz, O.; Christensen, A. E.; Danielsen, F.; Dawson, N.; Xaydongvanh, P. A combination of methods needed to assess the actual use of provisioning ecosystem services. Ecosystem Services, 17, 75-86, 2016. doi: 10.1016/j.ecoser.2015.11.005

Rosa, J. C. S.; Geneletti, D.; Morrison-Saunders, A.; Sánchez, L. E.; Hughes, M. To what extent can mine rehabilitation restore recreation services provided by a forest? Learning from 50 years of practice in southwest Australia. Land Use Policy, 90, 104290, 2020. doi: 10.1016/j.landusepol.2019.104290

Rosa, J. C. S.; Sánchez, L. E. Is the ecosystem services concept improving environmental impact assessment? Evidence from recent international practice. Environmental Impact Assessment Review, 50, 134-142, 2015. doi: 10.1016/j. eiar.2014.09.006

Rosa, J. C. S.; Sánchez, L. E. Advances and challenges of incorporating ecosystem services into impact assessment. Journal of environmental management, 180, 485-492, 2016. doi:10.1016/j.jenvman.2016.05.079

Rosa, J. C. S.; Sánchez, L. E.; Morrison-Saunders, A. Getting to "agreed" post-mining land use - An ecosystem services approach. Impact Assessment Project Appraisal, 36(3), 220-229, 2018. doi: 10.1080/14615517.2018.1445175

Rosenthal, A.; Verutes, G.; Mckenzie, E.; Arkema, K. K.; Bhagabati, N.; Bremer, L. L.; Olwero, N.; Vogl, A. L. Process matters: a framework for conducting decision-relevant assessments of ecosystem services. International Journal of Biodiversity Science, Ecosystem Services \& Management, 11(3), 190-204, 2015. doi: 10.1080/21513732.2014.966149

Sánchez, L. E. Avaliação de impacto ambiental. São Paulo: Oficina de Textos, 2013.
Sheate, W. R.; Eales, R. P.; Daly, E.; Baker, J.; Murdoch, A.; Hill, C.; Karpouzoglou, T. Spatial representation and specification of ecosystem services: a methodology using land use/land cover data and stakeholder engagement. Journal of Environmental Assessment Policy and Management, 14(1), 1250001, 2012. doi: 10.1142/S1464333212500019.

Tallis, H.; Polasky, S.; Lozano, J. S.; Wolny, S. Inclusive Wealth Accounting for Regulating Ecosystem Services in Inclusive Wealth Report 2012: Measuring Progress towards Sustainability. Cambridge UK: Cambridge University Press, 2012. Disponível em <https://digitallibrary.un.org/ record/784798? $\ln =\mathrm{en}>$. Acesso em: mar. 2020.

Treweek, J. Ecological Impact Assessment. Malden, MA, US: Blackwell Science, 1999.

Vasuki, Y.; Yu, L.; Holden, E.; Kovesi, P.; Wedge, D.; Grigg, A. H. The spatial-temporal patterns of land cover changes due to mining activities in the Darling Range, Western Australia: A visual analytics approach. Ore Geology Reviews, 8, 23-32, 2018. doi: 10.1016/j.oregeorev.2018.07.001

Wang, S. D.; Liu, C. H.; Zhang, H. B. Suitability evaluation for land reclamation in mining area: A case study of Gaoqiao bauxite mine. Transactions of Nonferrous Metals Society of China, 21, s506-s515, 2011. doi: 10.1016/S10036326(12)61633-1 


\section{Anexo 1}

Roteiro de entrevistas semiestruturada utilizado para identificação de beneficiários - Mina de Bauxita Juruti

Perguntas "quebra gelo"

Ficha $\mathrm{N}^{\mathrm{o}}$ Comunidade

1. Você nasceu em Juruti?

$\square \operatorname{Sim} \square$ Não, mora aqui há quanto tempo?

2. Onde morava antes?

Serviços culturais

3. Quais as principais atividades de lazer ou recreação da comunidade?

Atualmente

Onde?

Antes:

A distância mudou?

4. Como vocês utilizam ou utilizavam florestas para alguma atividade cultural como festas etc.?

Atualmente:

Onde?

Antes: 
A distância mudou?

$\square$ Não utilizam.

Serviços provisão

5. Forma de abastecimento de água?
$\square$
Poço $\square$ Nascente
$\square$ Rio $\square$
Encanada
$\square$
Outro. Qual?

6. Quais os usos que você faz da água?

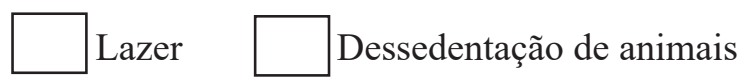

$\square$ Lavar roupas $\square$ Outros, quais? 


\begin{tabular}{|c|c|c|c|c|c|c|}
\hline Serviços & Quais? & Nos platôs? & E agora onde? Aumentou a distância? & Frequência? & Quantidade? & Destino? \\
\hline Fibras e Resinas & & & & & & \\
\hline Plantas medicinais & & & & & & \\
\hline $\begin{array}{l}\text { Frutos, sementes, } \\
\text { castanhas }\end{array}$ & & & & & & \\
\hline Planta ornamental & & & & & & \\
\hline Lenha & & & & & & \\
\hline Madeira & & & & & & \\
\hline Peixes & & & & & & \\
\hline Tartaruga & & & & & & \\
\hline Outros? & & & & & & \\
\hline Culturas agrícolas & & & & & & \\
\hline
\end{tabular}


1. Dentre as atividades que você realizava nos platôs, quais você considera a mais importante e/ou que sente mais falta?

2. Gostaria de voltar a fazer?

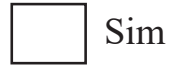
Não, por que?

3. Acha que seus filhos ou netos irão querer fazer essas atividades?

4. Você tem deixado de realizar alguma coisa, atividade ou produzir algo por causa da mineração? $\square \operatorname{Sim}$. O que?<smiles>C1C[Nb]C1</smiles>

5. 'O projeto de mineração atrapalha suas atividades atuais de alguma maneira? $\square$ Sim. Qual?

Como?

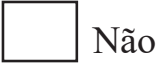

6. Como você gostaria que área que está minerada fosse devolvida para comunidade do PAE Juruti Velho? 
1- Idade do respondente

2- Número de pessoas na família

3- Sexo

4- Ocupação do respondente

5- Gostaria de falar mais alguma coisa? Alguma sugestão? 